\title{
Prevalence of Human Immune Deficiency among Registered Tuberculosis Patients across Pakistan during 2013-2015
}

-Prevalence of TB-HIV Co-Infection in Pakistan

\author{
Muhammad Aamir Safdar1*, Razia Fatima1, Nasir Mahmood Khan'1, Aashifa Yaqoob', \\ Afshan Khurshid ${ }^{2}$, Mahboob Ul Haq ${ }^{1}$, Ahmad Wali ${ }^{3}$ \\ ${ }^{1}$ National TB Control Program, Ministry of National Health Services Regulation \& Coordination, Islamabad, Pakistan \\ ${ }^{2}$ Provincial TB Control Program, Sindh, Pakistan \\ ${ }^{3}$ Provincial TB Control Program, Balochistan, Pakistan \\ Email: *aamirch@ntp.gov.pk, *aamirchmd@gmail.com
}

How to cite this paper: Safdar, M.A., Fatima, R., Khan, N.M., Yaqoob, A., Khurshid, A., Haq, M. and Wali, A. (2018) Prevalence of Human Immune Deficiency among Registered Tuberculosis Patients across Pakistan during 2013-2015. Journal of Tuberculosis Research, 6, 96-103. https://doi.org/10.4236/jtr.2018.61009

Received: February 2, 2018

Accepted: March 24, 2018

Published: March 27, 2018

Copyright (๑) 2018 by authors and Scientific Research Publishing Inc. This work is licensed under the Creative Commons Attribution International License (CC BY 4.0).

http://creativecommons.org/licenses/by/4.0/

\section{(c) (i) Open Access}

\begin{abstract}
The problem of Tuberculosis (TB) and Human Immune Deficiency Virus (HIV) co-infection becomes vital when it is seen in the context of under developed countries like Pakistan. Pakistan ranks $5^{\text {th }}$ high burden countries for drug-susceptible and $6^{\text {th }}$ among drug-resistant TB patients [1]. Objectives of the study were to assess the prevalence of TB-HIV Co-infection at the designated Sentinel Sites across Pakistan. A cross-sectional study is based on retrospective record review of routinely maintained TB program data at all 17 designated sentinel sites of TB Control Program from 2013-15. Among the screened TB patients $145(0.66 \%)$ were found HIV reactive. The prevalence of HIV was higher $(1.02 \%)$ in extra-pulmonary and male TB patients $(1.23 \%)$ as compared to pulmonary $(0.55 \%)$ and female patients $(0.09 \%)$. Scale up TB surveillance activities, integrating TB-HIV care services, active case finding among key affected populations will have a positive impact on TB-HIV co-infection and disease control.
\end{abstract}

\section{Keywords}

Tuberculosis, HIV, Co-Infection, Pakistan

\section{Background}

Globally, in 2015; 10.6 million Tuberculosis (TB) patients were reported, among them, 1.2 million (11\%) are living with Human Immunodeficiency Virus/Acquired 
Immune Deficiency Syndrome (HIV/AIDS) [1]. Pakistan is facing the challenge of the high burden of TB with a prevalence rate of 341/100,000 [1]. In Pakistan; HIV/AIDS epidemic is estimated to be less than $0.1 \%$ among general population and there is a shifting trend among people living with Human Immune deficiency (PLHIV) from "Low prevalence, high-risk key population" to a more concentrated epidemic [2].

Prevalence of TB-HIV co-infection is studied in few African studies where HIV prevalence is very high [3] [4] but similar studies have not been carried out in Pakistan, however, there are few similar studies in Asia [5] [6] [7].

In 2015; about 3,31,809 TB cases were notified by National TB Control program in Pakistan, and among them, 12,162 (3.6\%) were registered as TB patients which were screened for HIV at the designated sentinel sites in Pakistan [1]. World Health Organization End TB Strategy recommends all registered TB patients should be screened for HIV in the country [8]. This intervention is limited only to designated 17 sentinel sites across the country. Prevalence of HIV among TB patients is unknown in Pakistan. The Epidemic of TB control efforts can be managed by effectively identifying co-infected patients in the country. The concentrated epidemic of HIV among the key populations is a great challenge for the TB and AIDS Control Programs in Pakistan [2]. Current limited surveillance of TB-HIV co-infection is not reflective of spread and extent of co-infection in Pakistan. This study will generate evidence for policy reforms to address TB-HIV co-infection in the country.

Objective of the study was to determine the number and proportion of HIV reactive among notified TB patients and to assess pre \& posttest counseling, subsequent registration at ARV clinic and socio-demographic profile.

\section{Methods}

\subsection{Study Design}

A cross-sectional study based on retrospective record review of routinely maintained programme data of Pakistan from 2013-2015. In the study children age, less than 14 years were excluded.

\subsection{Data Collection and Validation}

The aggregate data was extracted from the TB-HIV register. Data were double entered in EPI data software version 3.1 and analyzed in SPSS ver 16 and descriptive statistics were done to assess the characteristic of TB-HIV cases in Pakistan.

\subsection{HIV Test}

At designated TB-HIV sentinel sites across Pakistan all registered TB patients are offered HIV screening with the opt-out option and they were screened by WHO recommended rapid diagnostic kits (RDT) and according to National HIV testing and counseling (HTC) strategy, Test $1=$ Alere Determine HIV-1/2 
$\mathrm{Ag} / \mathrm{Ab}$ Combo (Sensitivity > 99\%) [9]. From the verbally consented patients, pretest counseling is done with all registered TB Patients. Once the screening has been done all HIV reactive and non-reactive patients are further followed in the posttest counseling. Registered TB patient found Reactive was now referred to TB-HIV linked centers i.e., Anti Retro Viral (ARV) Clinics for further confirmation through Test $2 \& 3$ as per HTC Guidelines [9] and those found confirmed they are registered for further continuation of treatment at those ARV clinics (Figure 1).

\subsection{Analysis and Statistics}

The aggregative data was extracted from the TBHIV register? Data were double entered in EPI data software version 3.1 and analyzed in SPSS ver 16 and descriptive statistics were done to assess the characteristic of TB/HIV cases in $\mathrm{Pa}$ kistan.

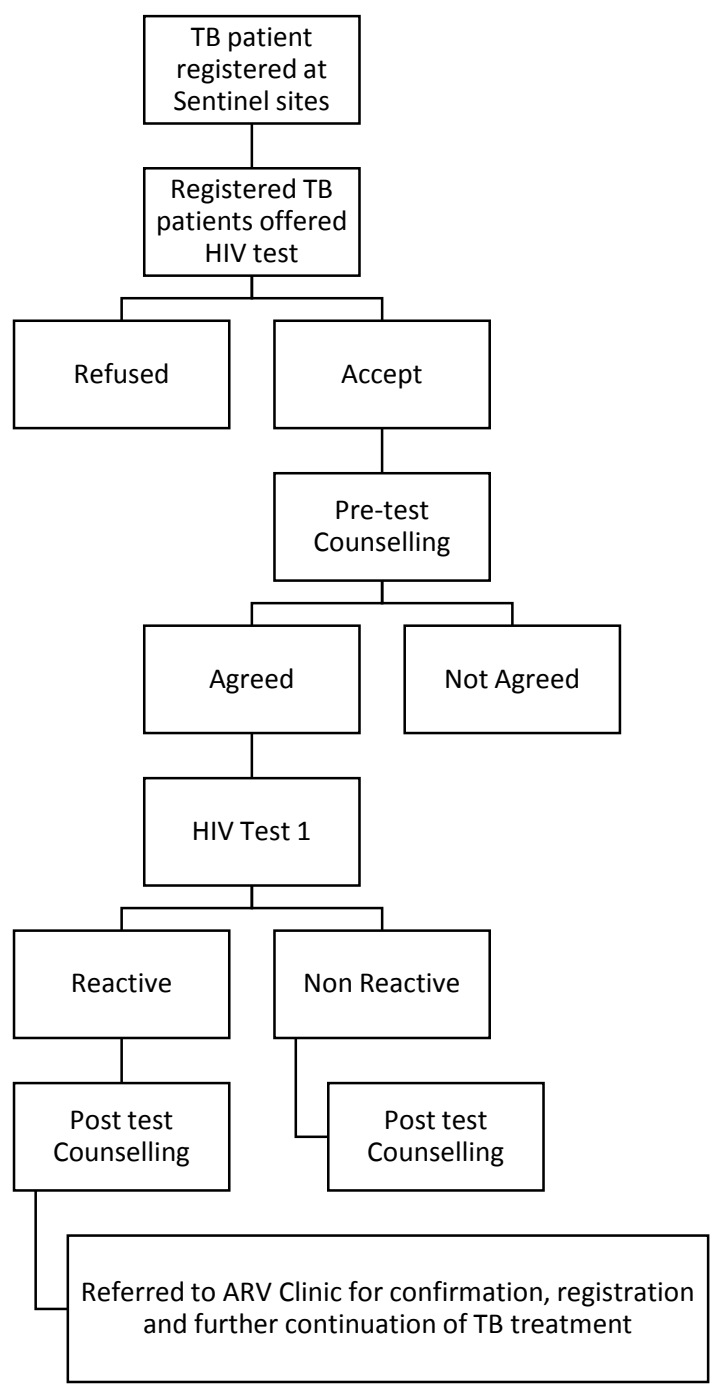

Figure 1. Flow diagrams of TB patient's registration and HIV testing at sentinel sites in Pakistan. 


\subsection{Ethics Approval}

Permission to use the data and a local ethics exemption was obtained from the National TB control program. Since the study involved a review of records with no patient interaction, the informed consent was not required.

\section{Results}

A Total of 22,784 TB patients were registered at 17 designated sentinel sites in Pakistan from 2013-15, out of which $73.69 \%$ were pulmonary and $26.31 \%$ were Extra-pulmonary (Table 1). All registered TB patients were offered HIV screening out of which $94.6 \%$ accepted HIV counseling and testing. Among those screened $145(0.66 \%)$ TB patients were found reactive for TB-HIV Co-infected. The prevalence of HIV among Extrapulmonary TB patients was slightly higher than pulmonary patients ( $1.02 \%$ vs $0.55 \%)$ (Table 1$)$. The prevalence among B + ve was slightly higher as compared to clinically diagnosed $(0.32 \%$ vs $0.23 \%)$ (Table 1). The prevalence of HIV was significantly higher among males (1.23\%) as compared to female $(0.09 \%)$. Out of 145 reactive HIV patients, only 113 (77.9\%) reactive patients were found registered at ARV clinics for further treatment (Table 1).

Table 1. Description of TB patients screened, diagnosed and registered for HIV at Sentinel sites in Pakistan from 2013-15.

\begin{tabular}{|c|c|}
\hline & n (\%) \\
\hline Total registered TB patients & 22,874 \\
\hline \multicolumn{2}{|l|}{ Counseling for HIV screening } \\
\hline Accepted & $21,644(94.62)$ \\
\hline Refused & $1230(5.38)$ \\
\hline \multicolumn{2}{|c|}{ Socio demographic characteristics of screened TB patients $(n=21,644)$} \\
\hline \multicolumn{2}{|l|}{ Sex } \\
\hline Male & $10,959(50.63)$ \\
\hline Female & $10,675(49.32)$ \\
\hline Unknown & $10(0.04)$ \\
\hline \multicolumn{2}{|l|}{ Age (years) } \\
\hline $14-34$ & $12,976(58.56)$ \\
\hline $35-54$ & $5651(26.10)$ \\
\hline$\geq 55$ & $3017(13.93)$ \\
\hline \multicolumn{2}{|l|}{ Classification of disease } \\
\hline Pulmonary & $15,950(73.69)$ \\
\hline $\mathrm{B}+$ & $10,876(68.18)$ \\
\hline Clinically diagnosed & $5074(31.81)$ \\
\hline Ext-pulmonary & $5694(26.31)$ \\
\hline
\end{tabular}




\section{Continued}

\begin{tabular}{|c|c|}
\hline Province & \\
\hline Balochistan & $608(2.81)$ \\
\hline ICT & $1576(7.28)$ \\
\hline KPK & $1168(5.40)$ \\
\hline Punjab & $12,225(56.48)$ \\
\hline Sindh & $6067(28.03)$ \\
\hline HIV reactive & $145(0.66)$ \\
\hline \multicolumn{2}{|c|}{ Socio-demographic characteristics of TB-HIV reactive patients $(n=145)$} \\
\hline \multicolumn{2}{|l|}{ Sex } \\
\hline Male & $135(1.23)$ \\
\hline Female & $10(0.09)$ \\
\hline \multicolumn{2}{|l|}{ Age (years) } \\
\hline $14-34$ & $91(0.70)$ \\
\hline $35-54$ & $49(0.87)$ \\
\hline$\geq 55$ & $5(0.17)$ \\
\hline \multicolumn{2}{|l|}{ Province reactive HIV } \\
\hline Balochistan & $7(1.15)$ \\
\hline ICT & $5(0.32)$ \\
\hline KPK & $6(0.51)$ \\
\hline Punjab & $92(0.75)$ \\
\hline Sindh & $35(0.58)$ \\
\hline \multicolumn{2}{|c|}{ Sputum results of $\mathrm{TB} / \mathrm{HIV}$ patients } \\
\hline Pulmonary & $87(0.55)$ \\
\hline $\mathrm{B}+$ & $51(0.32)$ \\
\hline Clinically diagnosed & $36(0.23)$ \\
\hline Extra-pulmonary & $58(1.02)$ \\
\hline Registered at ARV clinic & $113(77.9)$ \\
\hline
\end{tabular}

TB = Tuberculosis; HIV = Human Immune Deficiency Virus; ARV = Anti Retro Viral Therapy; $\mathrm{B}+=$ Bacteriological Positive; ICT = Islamabad Capital Territory; KPK = Khyber Phaktoon Khawa.

\section{Discussion}

The prevalence and extent of TB-HIV co-infection is limited in Pakistan, although HIV prevalence among key populations is concentrated [2]. In the present study prevalence of HIV among reactive patients is $0.66 \%$ which may reflect prevalence of TB-HIV co-infection in the country which is higher than prevalence among general population for HIV.2 Similar studies in Southeast Asia, Africa has also shown higher prevalence of HIV among TB patients [4] [10]. A higher rate of TB-HIV co-infection was noted in the reproductive age groups 14 - 54 in the study which is consistent with other studies in similar set- 
tings [4] [5] [10]. In the province of Balochistan highest prevalence was noted which is $1.15 \%$ followed by Punjab $0.75 \%$ and Sindh $0.58 \%$. Which is not reflective of prevalence among HIV patients in the country as intervention was limited only at established sentinel sites and usually key affected population did not visit TB clinics [2]. 94.6\% registered TB patients consented for HIV counselling and testing which is comparable with an Asian and African studies [4] [5] [10]. Among the reactive patients only $78.9 \%$ were confirmed and registered at Anti-Retroviral therapy (ARV) clinics for further registration and continuation of treatment which is less than Indian and Ethiopian studies [4] [10]. As majority of sentinel sites are not in the same facility and due to limited number of ARV clinics (23) which are established at concentrated epidemics cities in Pakistan, reason why around $21.1 \%$ of the HIV reactive patients were lost to follow up and not found registered for further confirmation and continuation of HIV care services.

In the present study among the pulmonary and extra-pulmonary TB patient's HIV reactive were $0.55 \%$ and $1.02 \%$ respectively which is lesser than other studies in India, Singapore, and Israel [9] [10]. Of the pulmonary patients $0.32 \%$ reactive were bacteriologically confirmed patients which is lesser also than other studies in Southeast Asia [4] [5]. The proportion of co-infection among males is (1.23\%) which is significantly higher as compared to females $(0.09 \%)$ that could be due to risky behaviors like injecting drug use and unsafe sex practices [2] [11].

In Pakistan; these key populations are concentrated geographically in different cities and this number is increasing and they are at increased risk to develop Tuberculosis [2].

The study used the National program data. Since the study is based on routinely program data the accuracy and completeness of data could not be ensured.

Delay in screening and integration has several consequences for both programs, including 1) progression of undetected infection among affected population, 2) increased the risk of poor treatment outcomes and higher mortality.4 Strategies are urgently needed to improve the screening of all registered TB patients for HIV at the time of registration.

\section{Limitation of Study}

The limitation of this study was non-availability of proper recording and reporting tools reason why data from all provinces were not available. Treatment outcomes of the reactive TB/HIV co-infected patients were also not available.

\section{Conclusion}

Due to limited screening among registered TB patients scale-up of surveillance activities, integrating TB and HIV care services, active case finding among key affected populations will have a positive impact on TB-HIV co-infection and disease control. 


\section{Acknowledgements}

This research was conducted through the Structured Operational Research and Training Initiative (SORT IT), a global partnership led by the Special Programme for Research and Training in Tropical Diseases at the World Health Organization (WHO/TDR). The training model is based on a course developed jointly by the International Union against Tuberculosis and Lung Disease (The Union, Paris, France) and Médecins Sans Frontières (MSF, Geneva, Switzerland). The specific SORT IT programme that resulted in this publication was implemented by the National Tuberculosis Control Programme of Pakistan, through the support of the Global Fund to Fight AIDS, Tuberculosis, and Malaria (The Global Fund, Geneva, Switzerland). I do hereby appreciate the support received from Abdullah, Ms. Sana Fatima and Dr. Muhammad Dost Khan for assisting me during the data collection and analysis.

\section{Budget}

The Global Fund will cover the publication fee.

\section{References}

[1] WHO (2016) Global TB Report 2016. WHO, Geneva.

[2] National AIDS Control Program (2011) HIV Second Generation Surveillance in Pakistan: National Report Round IV. National AIDS Control Program, Islamabad, 106.

[3] Tarekegne, D., Jemal, M., Atanaw, T., Ebabu, A., Endris, M., Moges, F., et al. (2016) Prevalence of Human Immunodeficiency Virus Infection in a Cohort of Tuberculosis Patients at Metema Hospital, Northwest Ethiopia: A 3 Years Retrospective Study. BMC Research Notes, 9, 192. https://doi.org/10.1186/s13104-016-2004-8 http://bmcresnotes.biomedcentral.com/articles/10.1186/s13104-016-2004-8

[4] Belay, M., Bjune, G. and Abebe, F. (2015) Prevalence of Tuberculosis, HIV, and TB-HIV Co-Infection among Pulmonary Tuberculosis Suspects in a Predominantly Pastoralist Area, Northeast Ethiopia. Global Health Action, 8, 1-7. https://doi.org/10.3402/gha.v8.27949

[5] Nandar, K., Ang, L.W., Tey, J., James, L., Kyi Win, K.M., Chee, C.B.E., et al. (2017) Epidemiology of Tuberculosis and HIV Coinfections in Singapore, 2000-2014. HIV Medicine, 19, 1-6.

[6] Zohar, M., Moshe, L., Daniel, C., Noa, C. and Itamar, G. (2014) HIV Prevalence in the Israeli Tuberculosis Cohort, 1999-2011. BMC Public Health, 14, 1090. http://bmcpublichealth.biomedcentral.com/articles/10.1186/1471-2458-14-1090 https://doi.org/10.1186/1471-2458-14-1090

[7] Gao, J., Zheng, P., Fu, H. and Zheng, J.C. (2013) Prevalence of TB/HIV Co-Infection in Countries Except China: A Systematic Review and Meta-Analysis. PLoS One, 8, e64915. https://doi.org/10.1371/journal.pone.0064915 https://www.ncbi.nlm.nih.gov/pmc/articles/PMC3669088/pdf/pone.0064915.pdf

[8] World Health Organization (2015) Implementing the End TB Strategy: The Essentials. WHO, Geneva, 1-130.

[9] World Health Organization (2015) Consolidated Guidelines on HIV Testing Services 2015. WHO, Geneva, $192 \mathrm{p}$. http://apps.who.int/iris/bitstream/10665/179870/1/9789241508926_eng.pdf?ua=1\& 
$\underline{\mathrm{ua}=1}$

[10] Manjareeka, M. and Nanda, S. (2013) Prevalence of HIV Infection among Tuberculosis Patients in Eastern India. Journal of Infection and Public Health, 6, 358-362. http://www.ncbi.nlm.nih.gov/pubmed/23999356 https://doi.org/10.1016/j.jiph.2013.04.004

[11] Strathdee, S.A., Hallett, T.B., Bobrova, N., Rhodes, T., Booth, R., Abdool, R., et al. (2010) HIV and Risk Environment for Injecting Drug Users: The Past, Present, and Future. Lancet, 376, 268-284. http://www.ncbi.nlm.nih.gov/pubmed/20650523 https://doi.org/10.1016/S0140-6736(10)60743-X 